\title{
Forecasting Deterioration of Bridge Components from Visual Inspection Data
}

\author{
Md Saeed Hasan, Sujeeva Setunge, David W. Law, and Yew-Chin Koay
}

\begin{abstract}
In order to extract the optimal output in the form of good management decisions with least resources, a bridge management system or BMS in short, is an essential part for every road transport authority. In a BMS, decisions regarding frequency of maintenance, conducting repairs and rehabilitation are based on inspection data collected for the bridges by trained inspectors following a condition rating method developed by the authority. The road authorities are constantly trying to convert these condition monitoring data to a meaningful practical decision supporting tool. To address this need, a study has been conducted to forecast deterioration of reinforced concrete bridge elements using Markov process. The aim of the research work is to identify the future maintenance needs utilizing the visual inspection data. Visual inspection data has been sourced from Victoria, Australia and transition matrices have been derived using Bayesian optimisation techniques of Markov chain model to predict the future condition of bridge components. Clustering of data with respect to input parameters such as era of construction, exposure conditions, annual average daily traffic and percentage of heavy vehicles can provide an improved deterioration model for bridge Engineers. Deterioration trends for three major structural components are presented in this paper.
\end{abstract}

Index Terms-Bridge deterioration, bridge management system, condition monitoring, markov chain.

\section{INTRODUCTION}

Whole of life care of bridge network requires an understanding of deterioration. Bridges are the key structural elements in the transportation system. They are considered to be vital links in any roadway network. Complete or partial failure to maintain these links paralyses the overall performance of the roadway network and causes excessive public and private losses. Therefore, bridge networks need to be managed in a way that ensures their uninterrupted performance throughout their design life. Maintenance of highway bridges plays an important role to assure the desirable service and adequate reliability of highway networks provided to the community. Thus determining a reliable bridge maintenance and rehabilitation strategy is of great importance.

A primary goal of a Bridge Management System (BMS) is to assist bridge managers in determining the best bridge maintenance, repair and rehabilitation strategy with respect to current or future bridge conditions. With restricted funds,

Manuscript received April 2, 2014; revised June 5, 2014

Md Saeed Hasan, Sujeeva Setunge, and David W. Law are with School of Civil, Environmental and Chemical Engineering, RMIT University, Melbourne, Australia (e-mail: m.hasan@student.rmit.edu.au).

Yew-Chin Koay is with Technical Services, Vicroads, Melbourne, Victoria, Australia. maximizing the effect of the investment on the improvement of serviceability and safety of the existing highway system is a major challenge for highway agencies. Transportation officials are continually dealing with intricate decisions involving whether to perform maintenance, rehabilitation, replacement, or a combination amid budgetary, political and other resource constraints. In addition, officials have to consider short-term and long-term solutions and their interrelationships to achieve overall cost-effective solutions. Therefore, it is imperative that a methodology be developed to aid bridge management officials especially at the project level in selecting the most appropriate bridge improvement alternatives. One essential requirement in this endeavour is service life estimates, which are required for life-cycle profiles, and in combination with cost estimates, to derive life-cycle costs.

Previously the BMS in most cases used to be based on a deterministic approach and the assessment of the reliability or the safety in general is based on subjective statements [1]. However, most recently researchers have tried to implement different techniques into BMS [2], [3]. Bridge management systems like PONTIS and BRIDGIT are stochastically based systems with rational assessment procedures [1]. These procedures set guidelines for data collection and reduce the subjective nature of data.

Min Liu, Dan M. [4] and Jung Baeg Son [5] fit regression prediction models based on Artificial Neural Network (ANN) techniques. However, the average prediction errors were up to 33.3\%. Other authors [6]-[8] use Markov Chain techniques to model bridge deterioration. The Pontis bridge management system uses Markov chain modelling to represent bridge deterioration in its analysis routines [9].

Another technique to model the deterioration of facility structures comprises Artificial intelligence (AI) which exploits computer techniques that aim to automate intelligent behaviours. AI techniques encompass expert systems, artificial neural networks (ANN), genetic algorithm (GA), and case based reasoning (CBR) to optimise the prediction of future conditions obtained through a set of observations. Researchers are using ANN to determine expected deterioration of bridge structure from existing condition data with respect to age along with other input parameter [2], [10].

\section{SIGNIFICANCE OF RESEARCH}

This research project aimed to use stochastic methods to predict deterioration curves for different components of concrete bridges in Victoria, Australia. The specific objective of the research is to develop a model to predict future condition of the concrete bridge structures from the available condition monitoring data. An attempt has been 
made to predict the future condition of the bridge components using Bayesian methodology. The Bayes theorem has been applied in conjunction with MetropolisHasting Algorithm to optimise the Markov model. This methodology has been used for deriving Markov model for three different components of concrete bridges.

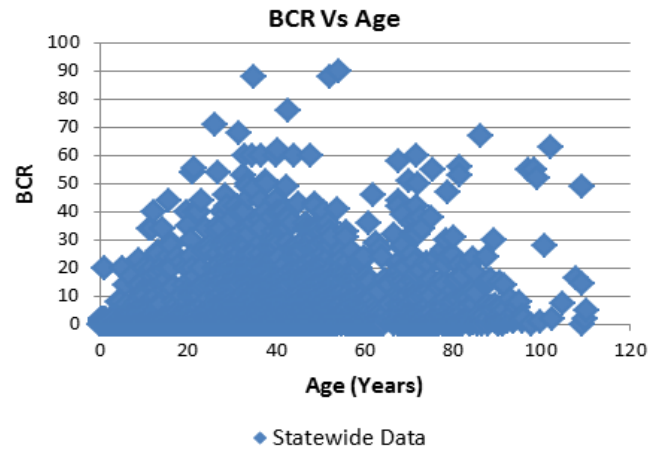

Fig. 1. Discrete relationship between age of the bridges and BCR when all records are considered.

The scope of the research is to enhance the decision making process using a Markov chain model for the use of road authorities from the available condition monitoring data which will significantly improve the reliability of the forecasts. It is very difficult to draw conclusive remark from the existing routine inspection data collected over a decade using simple techniques. From Fig. 1, it is clearly visible that drawing conclusive forecasting models is not possible using a deterministic method as there is no pattern. The coefficient of correlation is very poor for prediction purposes. Enhanced effort is required to understand and utilise this data.

\section{Methodology}

The data used in this study, provided by the road authorities of Victoria, Australia, were sourced from condition monitoring database collected over the period of 1995 to 2012. Analyses of three major structural elements, deck, abutment and girder are presented in this paper. Reviews of different methods of predicting deterioration were carried out to find the suitable technique for the available data sets. Firstly a deterministic approach were utilised to find any significant trend within the data set. After studying available literature, as a suitable means Markov method has been applied to this data set to predict the future condition of the bridge components using Bayesian approach where Metropolis Hasting algorithm were utilised.

\section{MARKov Decision PROCESS}

The Markov probability theory was created by Andrei A Markov (1907) who did significant research in probability and stochastic processes. Markov chain can be used to model the deterioration process which has been suggested by many researchers. The basic idea for modelling the deterioration process as a Markov chain process has been provided by Bogdanoff [11]. This process has been used to develop stochastic deterioration models for different infrastructure facilities. Markovian bridge deterioration models are based on the concept of defining states in terms of bridge condition ratings and obtaining the probabilities of a bridge condition changing from one state to another [12]. The Markov Chain is defined as a random process in which the probability that a certain future state will occur depends only on the present or immediately preceding state of the system, and not on the events leading up to its present state [13]. In other words, the analysis makes the assumption that given a present condition, the future is independent of the past. The result is a sequence of random events, but these events are related and similar to the original condition. Markov chains are proving effective in the engineering sciences as predicting algorithms for various infrastructures. Therefore, in this paper, the Markov model is used to predict the process of bridge deterioration as a discrete time condition state, where the condition of the bridge in the future is predicted using present conditions of the bridge while simultaneously being independent of its history.

Many researchers [14], [15] have suggested using Markov chain models in pavement management systems at earlier times. Jiang [12] has introduced Markov chain methodology to BMS in a similar fashion. A significant amount of research has been done in the application of the Markov chain theory in the infrastructure area. Micevski et al., [16] successfully modelled the deterioration of storm water pipes using the Markov model utilizing the Metropolis-Hastings Algorithm (MHA), one of the Markov chain Monte Carlo methods for calibration. Baik [17] developed a Markov chain based deterioration model for wastewater systems, and its transition probabilities were computed by ordered probit model (OPM). In an integrated pavement management system application, pavement deterioration prediction was performed by applying a discrete-time Markov model [18]. Kleiner et al. [19] simulated the deterioration of infrastructure assets using a semi-Markov model, which is a non-stationary, timedependent transition process.

A Markov process describes a system that can be in one of several states, and can pass from one state to another each time step according to fixed probabilities. To illustrate Markov process consider a system which is in state $i$, there is a fixed probability, pij, of it going into next state $\mathrm{j}$ with a single time step, and pij is called a transition probability.

One biggest challenge of using Markov model is its calibration. By the term calibration it is clearly understandable that it is the task of applying selective technique to estimate the model parameters or the transition probability. In this study Markov matrices have been calibrated with most optimised algorithm for attaining the most appropriate model for predicting the future condition rating of the bridges. The calibration technique using the Bayesian Markov chain Monte Carlo simulation was used to achieve the transition probability matrix from the existing condition monitoring data. The Metropolis-Hastings algorithm (MHA), a member of the MCMC simulation [20], was chosen to perform sampling from the posterior distribution.

\section{DATA Processing}

In this research paper condition monitoring data of precast deck/slab (8P), precast girder (2P) and cast-in-situ 
abutment $(24 \mathrm{C})$ were analysed. The maintenance history is not available for this data set although most of the bridges are experiencing regular routine maintenance. To overcome this problem in this analysis overall condition rating (OCR) of components were calculated and compared with the successive inspection record. The component which shows an improvement in the OCR has been removed from the calculation. Hence only the bridges that indicate a deterioration trend in their condition data were considered. The OCR value 1.0 indicates the bridge is in perfect condition which is also another indication of maintenance impact. To ensure the bridge is experiencing deterioration an attempt has been made to ignore the perfect condition bridges. Hence the data was filtered above a threshold value of OCR. Table I shows a typical sample raw data set.

TABLE I: SAMPLE DATA FOR PRECAST DECK/SLAB COMPONENT
\begin{tabular}{|l|l|l|l|l|l|l|l|}
\hline \multirow{2}{*}{$\begin{array}{l}\text { Built } \\
\text { Year }\end{array}$} & \multirow{2}{*}{$\begin{array}{l}\text { Inspection } \\
\text { Date }\end{array}$} & \multicolumn{3}{|c|}{ Condition } & & \\
\cline { 3 - 7 } & 1 & 2 & 3 & 4 & AADT & CV \\
\hline $30 / 6 / 80$ & $16 / 6 / 97$ & 0 & 85 & 15 & 0 & 101 & 0.26 \\
\hline $30 / 6 / 80$ & $1 / 8 / 05$ & 0 & 20 & 80 & 0 & 101 & 0.26 \\
\hline $2 / 4 / 70$ & $14 / 05 / 97$ & 45 & 55 & 0 & 0 & 412 & 0.13 \\
\hline $1 / 1 / 70$ & $15 / 08 / 05$ & 10 & 90 & 0 & 0 & 161 & 0.22 \\
\hline $1 / 01 / 70$ & $9 / 06 / 12$ & 0 & 10 & 90 & 0 & 161 & 0.22 \\
\hline
\end{tabular}

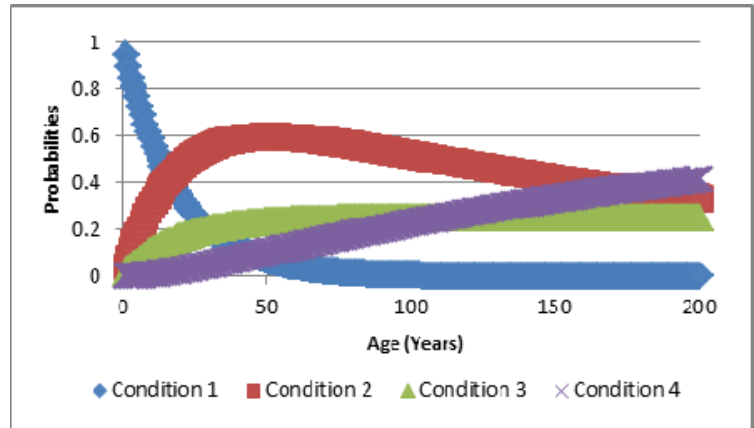

Fig. 2. Probability of staying in different condition of precast deck component (8P) for 200 years.

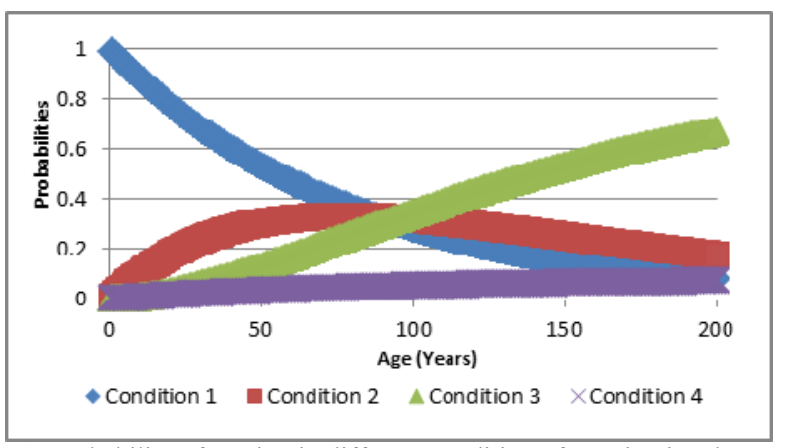

Fig. 3. Probability of staying in different condition of cast-in-situ abutment (24C) component for 200 years.

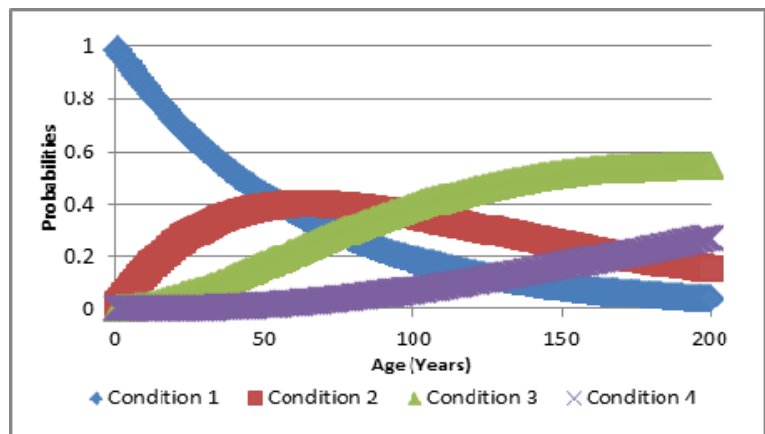

Fig. 4. Probability of staying in different condition of precast girder component (2P) for 200 years.

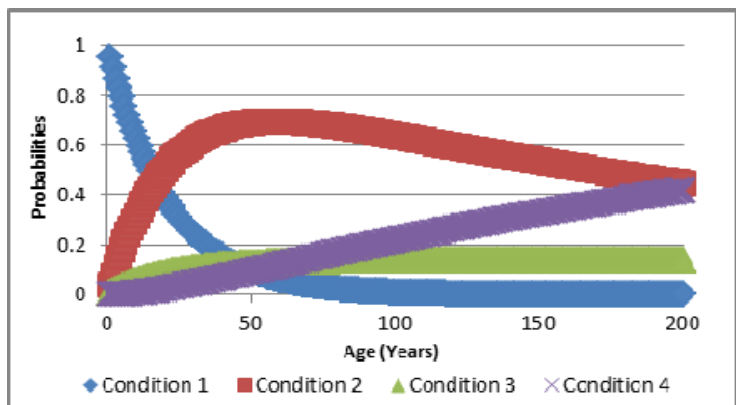

Fig. 5. Probability of staying in different condition of precast deck component for 200 years considering 1960-70 construction period.

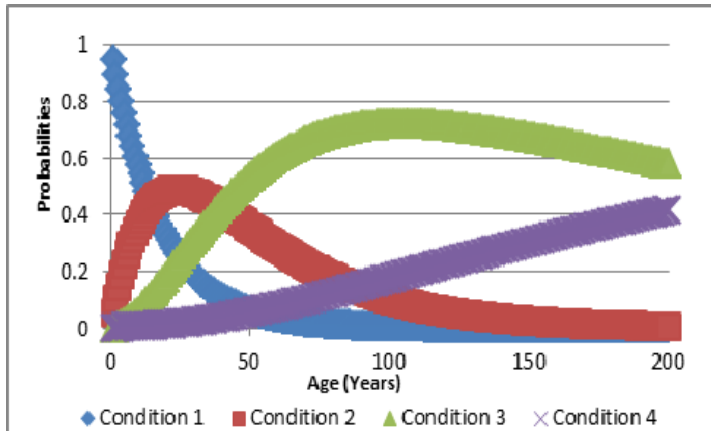

Fig. 6. Probability of staying in different condition of precast deck component for 200 years considering 1970-80 construction period.

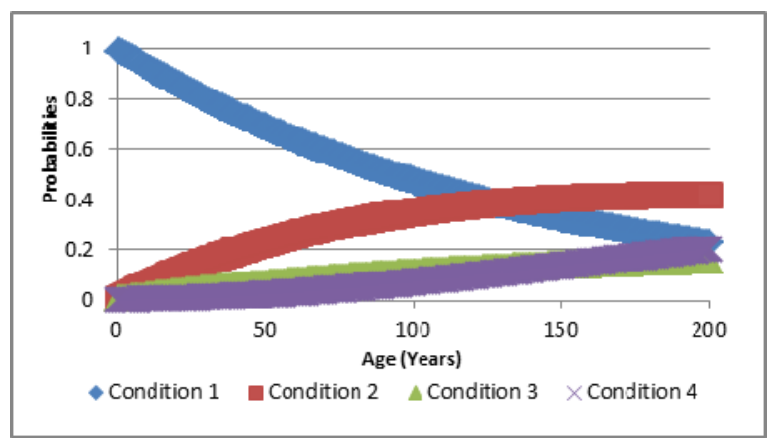

Fig. 7. Probability of staying in different condition of cast-in-situ Abutment component for 200 years considering 1950-60 construction period.

\section{RESUltS AND DISCUSSIONS}

Markov transition probability matrices have been used to estimate future probable condition for three different structural components, precast girder, precast deck/slab and cast-in-situ abutment using the complete state-wide data set. A two hundred year predictions are calculated which is represented graphically in Fig. 2, Fig. 3 and Fig. 4. Using these figures users can determine the probability of a structural component being in a given condition at a given age. A further clustering was applied on the data set using the construction period range, in this case 10 years, to identify any impacts of construction methods of bridges. Fig. 5 to Fig. 8 represents probability of different components to stay in four different conditions over a two hundred years span where only ten years interval data were considered.

Fig. 2 to Fig. 4 and the summary in Table II shows that deck/slab has a faster deterioration rate compared to abutment and girder which is expected in practice as deck/slab experiences the traffic loading directly.

Fig. 5 and Fig. 6 and summary in Table III presents transition probability of deck/slab constructed in two different time periods. The figure shows that bridge deck 
components built between 1960 to1970 have a slower deterioration trend compared to those built between 1970 to1980. However, Fig. 7 and Fig. 8 show that bridge abutment components built between 1950 and 1960 has similar deterioration trend with those built between 1960 and 1970. The data is affected by maintenance actions, which were not recorded with the raw data. However, improved condition rating over the period of time for successive inspection has been discarded from the model to overcome this issue. Moreover, a threshold value of OCR was considered to consolidate the maintenance impact. With collection and recording of maintenance data, road authorities would be able to refine these models with time.

TABLE II: SUMMARY OF COMPARISON OF CONDITION/AGE FOR FULL DATA SET

\begin{tabular}{|l|l|l|l|l|}
\hline $\begin{array}{l}\text { \% of components } \\
\text { in condition }\end{array}$ & Age & $8 \mathrm{P}$ & $24 \mathrm{C}$ & $2 \mathrm{P}$ \\
\hline \multirow{4}{*}{1} & 20 & 34.39 & 77.71 & 71.58 \\
\cline { 2 - 5 } & 50 & 6.93 & 53.24 & 43.36 \\
\cline { 2 - 5 } & 100 & 0.48 & 28.35 & 18.80 \\
\hline \multirow{4}{*}{3} & 20 & 46.83 & 18.06 & 24.67 \\
\hline \multirow{4}{*}{4} & 50 & 59.92 & 30.65 & 38.71 \\
\cline { 2 - 5 } & 100 & 52.02 & 32.12 & 35.65 \\
\hline \multirow{3}{*}{4} & 20 & 16.37 & 2.73 & 3.65 \\
\cline { 2 - 5 } & 50 & 23.26 & 12.84 & 16.67 \\
\cline { 2 - 5 } & 100 & 24.96 & 34.24 & 38.62 \\
\hline & 20 & 2.39 & 1.50 & 0.09 \\
\cline { 2 - 5 } & 50 & 9.86 & 3.27 & 1.26 \\
\cline { 2 - 5 } & 100 & 22.52 & 5.29 & 6.93 \\
\hline
\end{tabular}

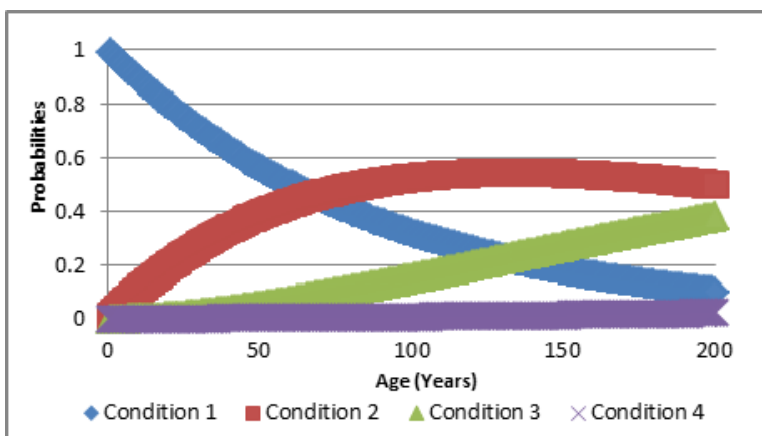

Fig. 8. Probability of staying in different condition of cast-in-situ abutment component for 200 years considering 1960-70 construction period.

TABLE III: COMPARISON OF EFFECT OF CONSTRUCTION ERA ON DETERIORATION 8P ELEMENTS

\begin{tabular}{|l|l|l|l|}
\hline $\begin{array}{l}\text { \% of component } \\
\text { in condition }\end{array}$ & Age & $1960-1970$ & $1970-1980$ \\
\hline \multirow{4}{*}{1} & 20 & 39.04 & 32.81 \\
\cline { 2 - 4 } & 50 & 9.52 & 6.17 \\
\cline { 2 - 4 } & 100 & 0.91 & 0.38 \\
\hline \multirow{4}{*}{3} & 20 & 50.47 & 48.25 \\
\hline \multirow{4}{*}{4} & 50 & 68.97 & 35.51 \\
\cline { 2 - 4 } & 100 & 63.83 & 10.23 \\
\hline \multirow{3}{*}{4} & 20 & 8.39 & 17.85 \\
\cline { 2 - 4 } & 50 & 12.45 & 53.01 \\
\cline { 2 - 4 } & 100 & 13.63 & 72.07 \\
\hline & 20 & 2.10 & 1.09 \\
\cline { 2 - 4 } & 50 & 9.06 & 5.32 \\
\cline { 2 - 4 } & 100 & 21.63 & 17.32 \\
\hline
\end{tabular}

\section{CONCLUSION}

The core element of a BMS is the database containing physical condition data obtained through regular inspection and maintenance activities over a significant amount of time. The reliability of a BMS is greatly dependent on the quality and accuracy of the bridge inventory and physical condition data obtained through field inspections [21].

The work presented here demonstrates that a stochastic method such as Markov chain can be used to forecast deterioration of bridge elements with time. Clustering of data with respect to input parameters such as era of construction, exposure conditions, annual average daily traffic and percentage of heavy vehicles can provide an improved deterioration model for bridge Engineers. However, linking maintenance actions to inspection data is extremely important to provide a reliable estimate of the deterioration.

\section{REFERENCES}

[1] P. T. Christensen, "Bridge management systems, present and future," Recent Advances in Bridge Engineering, The US-Europe Workshop on Bridge Engineering, 1996.

[2] J. O. Sobanjo, "A neural network approach to modeling bridge deterioration," in Proc. 4th Congress on Computing in Civil Engineering, ASCE, Reston, 1997, pp. 623-626.

[3] O. B. Tokdemir, C. Ayvalik, and J. Mohammadi, "Prediction of highway bridge performance by artificial neural networks and genetic algorithms," in Proc. the 17th International Symposium on Automation and Robotics in Construction ISARC, Taipei, Taiwan, 2000.

[4] M. Liu and D. M. Frangopol, "Optimal bridge maintenance planning based on probabilistic performance prediction," Engineering Structures, vol. 26, pp. 991-1002, June 2004.

[5] J. B. Son, J. Lee, M. Blumenstein, Y. C. Loo, H. Guan, and K. Panuwatwanich, "Generating historical condition ratings for the reliable prediction of bridge deteriorations," IABSE Symposium Report, International Association for Bridge and Structural Engineering, pp. 44-53, 2009.

[6] G. Morcous, "Performance prediction of bridge deck systems using markov chains," Journal of Performance of Constructed Facilities, ASCE, vol. 20, pp. 146-155, 2006.

[7] P. Basheer, S. Chidiact, and A. Long, "Predictive models for deterioration of concrete structures," Construction and Building Materials, vol. 10, pp. 27-37, 1996.

[8] V. Patidar, S. Labi, K. Sinha, and P. Thompson, "NCHRP report 590: Multiple-objective optimization for bridge management systems," Transportation Research Board of the National Academies, Washington, DC, 2007.

[9] P. D. Thompson, E. P. Small, M. Johnson, and A. R. Marshall, "The Pontis bridge management system," Structural Engineering International, IABSE, vol. 8, pp. 303-308, 1998.

[10] J. Cattan and J. Mohammadi, "Analysis of bridge condition rating using neural networks," Computer-Aided Civil and Infrastructure Engineering, vol. 12, pp. 419-429, 1997.

[11] J. L. Bogdanoff, “A new cumulative damage model, Part 1,” Journal of Applied Mechanics, vol. 45, pp. 246-250, June 1978.

[12] Y. Jiang, "The development of performance prediction and optimization models for bridge management systems," Ph.D. Dissertation, Purdue University, United States, Indiana, 1990.

[13] S. Ramani, "A markov-based analysis of the state of Ohio's bridge inventory and novel approaches to the estimation of bridge degradation rates," M.S. thesis, Dept. Elect. Eng., University of Cincinnati, Ohio, 2010.

[14] K. Golabi, R. B. Kulkarni, and G. B. Way, "A statewide pavement management system," Interfaces, vol. 12, pp. 5-21, 1982.

[15] J. V. Carnahan, W. J. Davis, M. Y. Shahin, P. L. Keane, and M. I. Wu, "Optimal maintenance decisions for pavement management," Journal of Transportation Engineering-ASCE, vol. 113, pp. 554-572, 1987.

[16] T. Micevski, G. Kuczera, and P. Coombes, "Markov model for storm water pipe deterioration," Journal of Infrastructure Systems, vol. 8, pp. 49-56, 2002. 
[17] H. S. Baik, H. S. Jeong, and D. M. Abraham, "Estimating transition probabilities in Markov chain-based deterioration models for management of wastewater systems," Journal of Water Resources Planning and Management, vol. 132, pp. 15-24, 2006.

[18] K. A. Abaza, S. A. Ashur, and I. A. Al-Khatib, "Integrated pavement management system with a Markovian prediction model," Journal of Transportation Engineering, vol. 130, pp. 24-33, 2004.

[19] Y. Kleiner, R. Sadiq, and B. Rajani, "Modelling the deterioration of buried infrastructure as a fuzzy Markov process," Journal of Water Supply: Research \& Technology-Aqua, vol. 55, 2006.

[20] A. Gelman, J. B. Carlin, H. S. Stern, D. B. Dunson, A. Vehtari, and D. B. Rubin, Bayesian Data Analysis, CRC Press, 2013.

[21] AASHTO, "Manual for condition evaluation of bridges," American Association of State Highway and Transportation Officials, AASHTO, Washington, D.C., 1994.

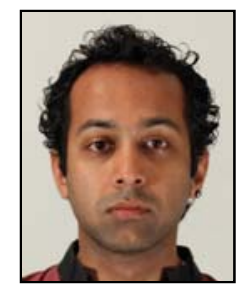

Md Saeed Hasan was born in Bangladesh in January 1984 . He is currently doing his PhD study at RMIT University, Melbourne under the supervision of professor Sujeeva Setunge. He finished his masters from RMIT University in 2010. During his masters he tried to predict the life expectancy of concrete septic tanks in Victoria, Australia using experimental approach. Currently he is doing his research in concrete Bridge Management area. He has keen interest on concrete technology and structural integrity based research.

He has worked in a Telecom Operator company in Bangladesh and supervised the construction of telecom tower. He has also working experience in pre-cast concrete super T-beam industry for road structure in Melbourne, Australia.

Mr. Hasan has published one paper in Magazine of Concrete Research titled "Predicting Life Expectancy of Concrete Septic Tanks Exposed to Sulphuric Acid Attack". 